\title{
Strain rate effects on tensile strength of iron green bodies
}

\author{
Masahiro Nishida $^{1, \text { a }}$, Yuki Kuroyanagi ${ }^{1}$, Hans-Åke Häggblad ${ }^{2}$, Pär Jonsén ${ }^{2}$, and Gustaf Gustafsson ${ }^{2}$ \\ ${ }^{1}$ Nagoya Institute of Technology, Gokiso-cho, Showa-ku, Aichi 466-8555, Japan \\ ${ }^{2}$ Luleå University of Technology, Division of Mechanics of Solid Materials, SE-97187 Luleå, Sweden
}

\begin{abstract}
Impact tensile strength of iron green bodies with densities of 7.2 and $7.4 \mathrm{~g} / \mathrm{cm}^{3}$ was examined by Brazilian test using the split-Hopkinson pressure bar (Kolsky bar) method. The powder material used for the experiments was a press-ready premix containing Distaloy AE, graphite, and lubricant. During dynamic compression, the failure behavior of specimens was observed using a high-speed video camera. The failure stress and failure behavior of dynamic compressive tests were compared with those of static compressive tests.
\end{abstract}

\section{Introduction}

Powder metallurgy is the serial process of blending fine powders (mixture), compressing them into a desired shape (compacting), and then heating the compressed material (sintering). This results in great advantages such as product cost effectiveness and product uniqueness. In general, parts created by powder metallurgy have low strength because they have relatively low density and high porosity. The production of high-strength parts having complex shapes is required. In order to increase both strength and density, new techniques such as high velocity compaction (HVC) were developed and further investigation has been conducted on the improvement of techniques and optimum conditions using computer simulation. The authors' group has been examining the strain rate sensitivity of uniaxial failure strength and determination of material parameter of unsintered compacted powder objects made of iron (ironbased powder compacts), so-called "green bodies" in the field of powder metallurgy, at high strain rates [1].

In this study, impact tensile strength of iron green bodies was measured by Brazilian test using the splitHopkinson pressure bar (Kolsky bar) method, so-called impact splitting test. The powder material used for the experiments was a press-ready premix containing Distaloy $\mathrm{AE}$, graphite (uf-4), and lubricant (Kenolube). Iron green bodies with densities of 7.2 and $7.4 \mathrm{~g} / \mathrm{cm}^{3}$ were employed. During dynamic compression, the failure behavior of specimens was also observed using a high-speed video camera. The failure stress and failure behavior of dynamic compressive tests were compared with those of static compressive tests.

\section{Experimental method}

In order to measure tensile strength of brittle materials at high strain rates, the spalling tests of long bar specimens (for example, ceramic [2-4], glass [5], concrete [6-8], and so on) and the Brazilian tests using the split-Hopkinson

\footnotetext{
${ }^{a}$ Corresponding author: nishida.masahiro@nitech.ac.jp
}

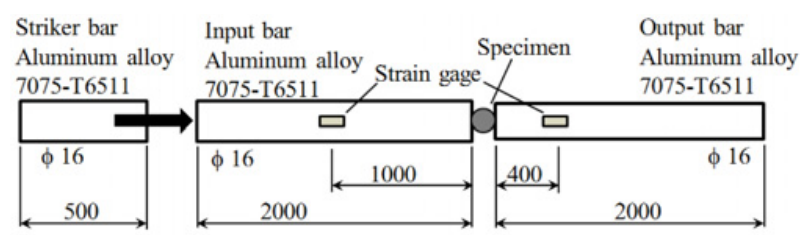

(a) Size of striker, input bar, and output bar

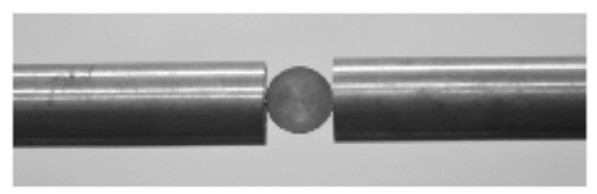

(b) Photograph near specimen

Figure 1. Experimental set up for Brazilian tests using splitHopkinson pressure bar.

pressure bar (for example, ceramic [9] and concrete [10-15] before or during 2001) are often used. Because it is difficult to make long green bodies (long specimens) with a homogeneous density for specimens of the spalling tests, we employed the Brazilian tests using the split-Hopkinson pressure bar for measuring tensile strength of iron green bodies, even though specimens during experiments are under the biaxial stress state.

Figure 1 shows a split-Hopkinson bar test as the Brazilian test. The diameters and lengths of input and output bars were $16 \mathrm{~mm}$ and $2000 \mathrm{~mm}$, respectively. Strain gages were applied to both sides of the input and output bars at distances of $1000 \mathrm{~mm}$ and $400 \mathrm{~mm}$ from the disc specimen, respectively. The input and output bars were made of aluminum alloy (7075-T6511). The applied force $F$ and displacement $x$ of the specimens were calculated from the strains of the bars measured by strain gauges, based on the following equations $[16,17]$ :

$$
\begin{gathered}
F_{a v}(t)=A E \varepsilon_{T}(t) \\
x_{a v}(t)=c_{3} \int_{0}^{t}\left[\varepsilon_{I}(t)-\varepsilon_{R}(t)-\varepsilon_{T}(t)\right] d t .
\end{gathered}
$$

This is an Open Access article distributed under the terms of the Creative Commons Attribution License 4.0, which permits unrestricted use, distribution, and reproduction in any medium, provided the original work is properly cited. 
Table 1. Material constants of input and output bars used in calculation.

\begin{tabular}{|c|c|c|}
\hline Density & $\begin{array}{c}\text { Elastic wave } \\
\text { velocity in bar }\end{array}$ & $\begin{array}{c}\text { Young's } \\
\text { modulus } E\end{array}$ \\
\hline $2.77 \times 10^{3} \mathrm{~kg} / \mathrm{m}^{3}$ & $5150 \mathrm{~m} / \mathrm{s}$ & $73.6 \mathrm{GPa}$ \\
\hline
\end{tabular}

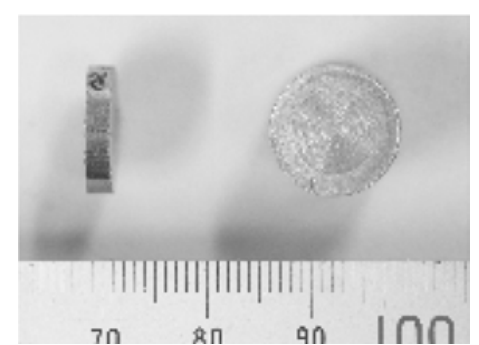

Figure 2. Photograph of disc specimen.

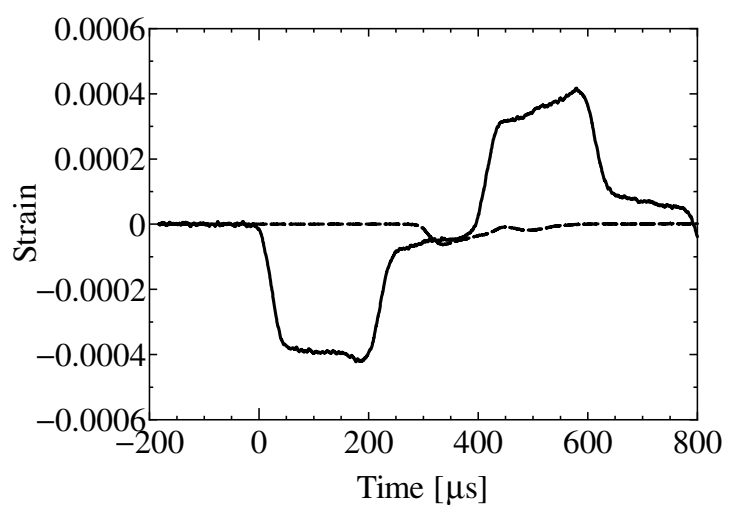

Figure 3. Strain histories of strain gauges for specimens with $7.2 \mathrm{~g} / \mathrm{cm}^{3}$ (Solid line: input bar; dashed line: output bar).

Here, $\varepsilon_{I}, \varepsilon_{R}$, and $\varepsilon_{T}$ denote the axial strains induced in the input bar by the incident wave and reflection wave, and in the output bar by the transmitted wave, respectively. $E$ and $c_{3}$ respectively denote the Young's modulus and elastic wave velocity of the input and output bars. $A$ denotes the cross-sectional areas of the input/output bars. The material constants of the aluminum alloy (7075T6511) bars used in the calculations are listed in Table 1. Aluminum alloy (7075-T6511) strikers with a diameter of $16 \mathrm{~mm}$ and lengths of $500 \mathrm{~mm}$ were used. During dynamic compression, we observed failure behavior of specimens using a high-speed video camera (Photron FASTCAM$1024 \mathrm{PCI} 100 \mathrm{~K}$, frame rate of 18000 frames/sec).

The powder materials used in the experiments were a press-ready premix consisting of Distaloy AE, $0.5 \%$ graphite (uf-4), and $0.6 \%$ Kenolube. Distaloy AE is a prealloyed water atomized iron powder from Höganäs AB, Sweden. Kenolube is a lubricant from the same supplier. The theoretical pore-free density of this mix is $7.52 \mathrm{~g} / \mathrm{cm}^{3}$. The behavior in the compression state of powder mixes was characterized by static and dynamic tests. The static tests were performed in a universal testing machine.

Cylindrical disc specimens were manufactured with a height of $2.5 \mathrm{~mm}$ and a diameter of $12.5 \mathrm{~mm}$ with two different densities, 7.2 and $7.4 \mathrm{~g} / \mathrm{cm}^{3}$. A photograph of specimens is shown in Fig. 2. The specimens were

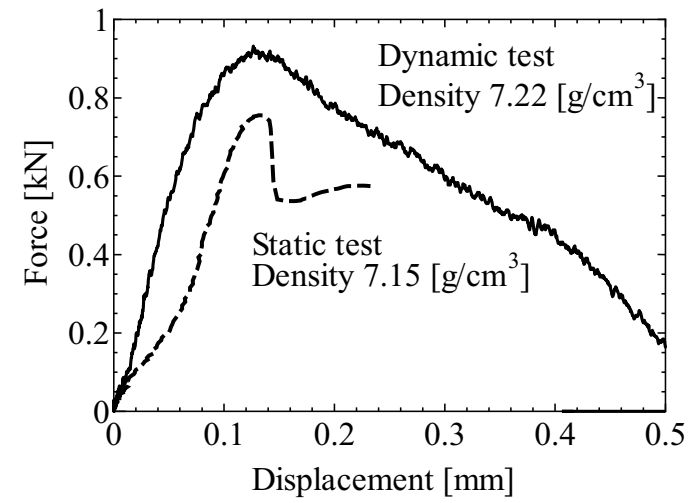

Figure 4. Force-displacement curves of specimen with $7.2 \mathrm{~g} / \mathrm{cm}^{3}$ (Compression speed of dynamic test $3.6 \mathrm{~m} / \mathrm{s}$, static test $0.002 \mathrm{~mm} / \mathrm{s}$ ).

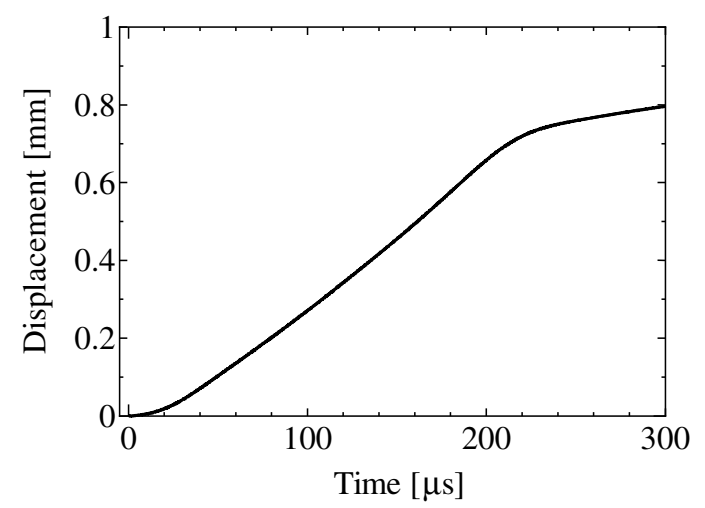

Figure 5. Displacement history of specimen with $7.2 \mathrm{~g} / \mathrm{cm}^{3}$ at high strain rate.

manufactured using a universal testing machine (DARTEC RK 250).

\section{Results and discussion}

Figure 3 shows strain histories of strain gauges using a specimen with a density of $7.2 \mathrm{~g} / \mathrm{cm}^{3}$. It was found from the reflection wave that displacement rate is almost constant. Figure 4 shows force-displacement curve for the specimen with a density of $7.2 \mathrm{~g} / \mathrm{cm}^{3}$ at a compression speed of $3.6 \mathrm{~m} / \mathrm{s}$. Compared with a static test result at a compression speed of $0.002 \mathrm{~mm} / \mathrm{s}$, the maximum stress (failure stress) increased with compression speed. Here, the compression speed was determined by a slope of displacement history in Fig. 5. The slope was almost constant. Figure 6 shows a force-displacement curve of the specimen with a density of $7.4 \mathrm{~g} / \mathrm{cm}^{3}$. In the case of density of $7.4 \mathrm{~g} / \mathrm{cm}^{3}$, the maximum stress (failure stress) also increased with compression speed. The measured maximum stresses are shown in Table 2. In the case of density of $7.2 \mathrm{~g} / \mathrm{cm}^{3}$, the maximum stress at high compression speed was 1.2 times larger than that at low compression speed. In the case of density of $7.4 \mathrm{~g} / \mathrm{cm}^{3}$, the maximum stress at high compression speed was 1.6 times larger than that at low compression speed. Regardless of compression speed, the maximum stress increased with density. 
Table 2. Maximum stress of impact splitting tests.

\begin{tabular}{|c|c|c|}
\hline & Low speed compression & High speed compression \\
\hline Lower & $0.76 \mathrm{kN}\left(7.15 \mathrm{~g} / \mathrm{cm}^{3}\right)$ & $0.96 \mathrm{kN}\left(7.22 \mathrm{~g} / \mathrm{cm}^{3}\right)$ \\
density & & $1.27 \mathrm{kN}\left(7.14 \mathrm{~g} / \mathrm{cm}^{3}\right)$ \\
\hline $\begin{array}{l}\text { Higher } \\
\text { density }\end{array}$ & $0.90 \mathrm{kN}\left(7.39 \mathrm{~g} / \mathrm{cm}^{3}\right)$ & $1.48 \mathrm{kN}\left(7.34 \mathrm{~g} / \mathrm{cm}^{3}\right)$ \\
\hline
\end{tabular}

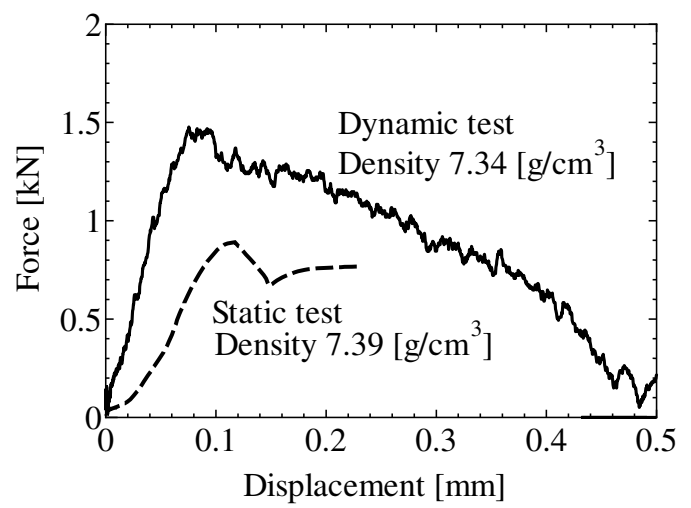

Figure 6. Force-displacement curves with specimen of $7.4 \mathrm{~g} / \mathrm{cm}^{3}$ (Compression speed of dynamic test $3.6 \mathrm{~m} / \mathrm{s}$, static test $0.002 \mathrm{~mm} / \mathrm{s}$ ).

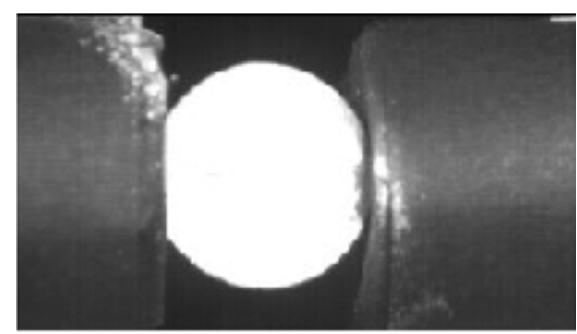

111 microseconds after onset of compression

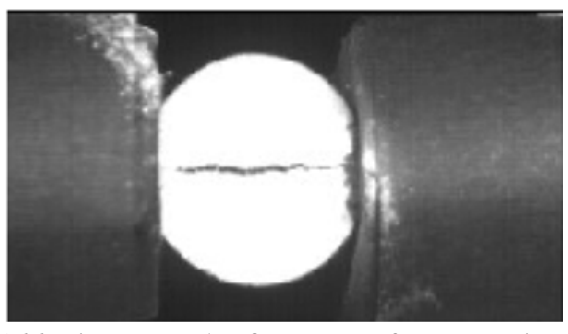

166 microseconds after onset of compression

Figure 7. Photographs of high-speed video camera with specimen of $7.14 \mathrm{~g} / \mathrm{cm}^{3}$, compression speed $3.1 \mathrm{~m} / \mathrm{s}$, lateral direction is compression direction.

Finally, Fig. 7 shows photographs (18,000 frames/ second) of specimens with a density of $7.14 \mathrm{~g} / \mathrm{cm}^{3}$ and maximum stress at $1.27 \mathrm{kN}$ in Table 2 , using a high-speed video camera. A crack began to form near the center of the specimen and moved in both directions along the central axis of the specimen. Failure behavior at high compression speed was almost the same as that at low compression speed in Fig. 8, with force-displacement shown in Fig. 4 and maximum stress is $0.76 \mathrm{kN}$, as shown in Table 2 .

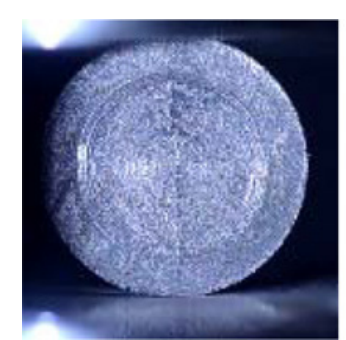

(a) Displacement $0.079 \mathrm{~mm}$

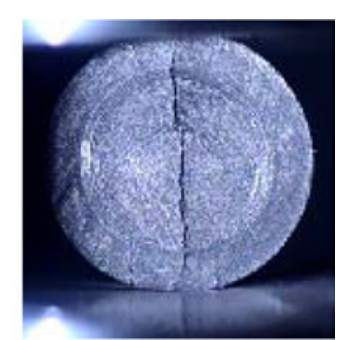

(b) Displacement $0.132 \mathrm{~mm}$
Figure 8. Photographs of static splitting test with specimen of $7.15 \mathrm{~g} / \mathrm{cm}^{3}$, vertical direction is compression direction.

\section{Conclusions}

The impact tensile strength of iron green bodies was measured by the impact splitting test and was compared with results of normal Brazilian test (static splitting test). The maximum stress (failure stress) also increased with compression speed. Even at high compression speed, the maximum stress (failure stress) increased with density. Failure behavior at high compression speed was almost the same as that at low compression speed.

The authors are greatly indebted to Professor Masashi Daimaruya of Muroran Institute of Technology for his valuable advice with respect to the split Hopkinson bar. The authors are also greatly indebted to Associate Professor Fumihiro Itoigawa of Nagoya Institute of Technology for his help with taking images using a high speed camera.

\section{References}

[1] G. Gustafsson, M. Nishida, H.-Å. Häggblad, H. Kato, P. Jonsén, T. Ogura, Powder Technology 268, 293 (2014)

[2] J. Najar, J. Phys. IV, Colloque C8, Supplément au Journal de Physique III, 4, 647 (1994)

[3] F. Díaz-Rubio Gálvez, J. Rodríguez, V. SánchezGálvez, J. Phys. IV, Colloque C3 Supplément au Journal de Physique III, 7, d'Août, 151 (1997)

[4] F. Díaz-Rubio Gálvez, J. Rodríguez, Pérez, V. Sánchez-Gálvez, Int. J. Impact Engineering, 27, 161 (2002)

[5] C. Johnstone, C. Ruiz, Int. J. Solids Struct., 32, 17/18 2647 (1995)

[6] M. Diamaruya, H. Kobayashi, T. Nonaka, J. Phys. IV, Colloque C3 Supplément au Journal de Physique III, 7, d'Août, 253 (1997)

[7] M. Daimaruya, H. Kobayashi, J. Phys. IV, 10 Pr9 173 (2000)

[8] A. Brara, J.R. Klepaczko, Mechanics of Materials, 38, 3253 (2006)

[9] T. Nojima, K. Ogawa, Proc. 4th Conference on Mechanical Properties of Materials at High Rates of Strain, J. Harding, ed.. Oxford, John Harding, 371 (1989)

[10] J.W. Tedesco, C.A. Ross, R.M. Brunair, Computers and Structures, 32, 3-4 609 (1989) 
[11] C.A. Ross, S.T. Kuennen and J.W. Tedesco, Micromechanics of Failure of Quasi-Brittle Materials, (eds. S.P. Shah, S.E. Swartz and M.L. Wang), Elsevier Applied Science 353 (1990)

[12] M.L. Hughes J.W. Tedesco C.A. Ross, Computers and structures, 47, 653 (1993)

[13] K. Jitsu, K. Shirai, C. Ito, H. Ohnuma, Proc. 9th symposium on impact problems in civil engineering, 4, 119 (1998) (in Japanese).
[14] D.E. Lambert and C.A. Ross, Int. J. Impact Engineering, 24, 985 (2000)

[15] M. Daimaruya, H. Kobayashi, H. Shizawa, R.A. Siriegar and Y. Ishihata, Proc. 10th International Congress on Fractures, (2001), CD-ROM

[16] G.T. Gray, III, ASM Handbook Vol. 8, Mechanical Testing and Evaluation, ASM 462 (2000)

[17] W. Chen, B. Song, Split Hopkinson (Kolsky) Bar: Design, Testing and Applications, Springer (2010) 